\title{
Organic matter in the Kavirondian sedimentary rocks of Archaean period in Kenya
}

\author{
YUUKo ITIHARA $^{1}$, KANENORI SUWA ${ }^{2}$ and Mitsuo Hoshino ${ }^{3}$ \\ Department of Geosciences, Faculty of Science, Osaka City University, Sumiyoshi-ku, Osaka $5588_{3}{ }_{3}^{1}$ \\ Department of Earth Sciences, Faculty of Science, Nagoya University, Chikusa-ku, Nagoya 464, \\ and Laboratory of Geology, College of General Education, Nagoya University, \\ Chikusa-ku, Nagoya $464,{ }^{3}$ Japan
}

(Received March 29, 1986: Accepted June 2, 1986)

\begin{abstract}
Concentrations and chemical forms of carbon and nitrogen are examined on the Kavirondian sedimentary rocks of Archaean period in Kenya (2,500-2,800Ma). Elemental composition and graphitization degree of kerogen fraction (carbonaceous matter) in the Kavirondian shales are also examined. Among various types of the sedimentary rocks, i.e., shales, sandstones, matrices of conglomerates and pyroclastics, only shales contain significant amounts of organic carbon and insoluble nitrogen in $\mathrm{KCl}$ solution. But their concentrations are low in comparison with those in Phanerozoic muddy sediments. The insoluble nitrogen is composed mainly of ammonium-nitrogen and contains a small amount of organic nitrogen. The ammonium-nitrogen must have been inherited from organic matters of sedimentary rocks as it is presumed from geochemical studies of nitrogen in Phanerozoic muddy sediments of Japan. The kerogen fractions in two Kavirondian shales are graphite, but their graphitization degree has not yet reached the fully ordered state. The graphitization degree is conformable with metamorphic grade of the shales. The elemental composition of the kerogen fractions shows that these kerogens have high $\mathrm{H} / \mathrm{C}$ ratio and low $\mathrm{N} / \mathrm{C}$ ratio in comparison with those of other Archaean shales in other areas.
\end{abstract}

\section{INTRODUCTION}

Phanerozoic muddy sediments contain considerable amounts of ammonium which were yielded from organic matter of the sediments. When the sediments are subjected to metamorphism, a large part of the ammonium is inherited by recrystallized minerals, mainly K-bearing minerals (Itihara and Honma, 1979, 1983). This finding suggests that ammonium is a clue to organic activities in the Precambrian. The ammonium contents of biotites in Precambrian rocks from Finland have been determined, to examine the possibility that ammonium in biotites represents a chemical fossil (Itihara and Suwa, 1985). Biotites from Proterozoic metasediments, which are originally products of sedimentation about 2,400-1,900 Ma ago, have high $\mathrm{NH}_{4}^{+}$contents $\left(\mathrm{n} \times 10^{2} \mathrm{ppm}\right)$, while biotites from Archaean metasediments of more than $2,600-2,800 \mathrm{Ma}$ old have only $\mathrm{n} \times 10 \mathrm{ppm}$ of $\mathrm{NH}_{4}^{+}$.

This study is purported to obtain reliable analyses on carbon and nitrogen in Archaean rocks to discuss organic activities in the early history of the earth. Carbon and nitrogen contents of various forms and elemental composition and graphitization degree of kerogen (carbonaceous matter) are examined on Archaean rocks in Kenya, in relation to the mineral composition and the metamorphic grade.

\section{Rock SAmples ANd Their Constituent MINERALS}

Rock samples were collected from the Kavirondian System by Suwa and Hoshino during geological survey on the Archaean greenstone belt in western Kenya in 1981. Geological setting of the Kavirondian System is summarized by Yanagi and Suwa (1981) and the 
Table 1. Metamorphic grade and constituent minerals of rock samples from the Kavirondian System.

Sample No.
Shale
1. Shale
2. Shale
3. Shale
Sandstone
4. Lithic sandstone
5. Lithic sandstone
6. Tuffaceous sandstone
7. Graywacke
Matrix of Conglomerate
8. Lithic sandstone
9. Lithic sandstone
10. Lithic sandstone
11. Arkosic sandstone
12. Graywacke
13. Graywacke
14. Graywacke
15. Tuffaceous sandstone
Pyroclastics
16. Tuff breccia
17. Tuff breccia

Metamorphic Facies

Lower Greenschist f. Higher Greenschist $f$. Higher Greenschist f.

Lower Greenschist f. Lower Greenschist $\mathrm{f}$. Higher Greenschist f. Lower Amphibolite f.

Lower Greenschist f. Lower Greenschist f. Higher Greenschist $f$. Lower Greenschist f. Lower Greenschist f. Lower Amphibolite f. Lower Amphibolite f. Lower Greenschist $f$.

Lower Greenschist $\mathrm{f}$. Higher Greenschist f.
Constituent minerals* 1

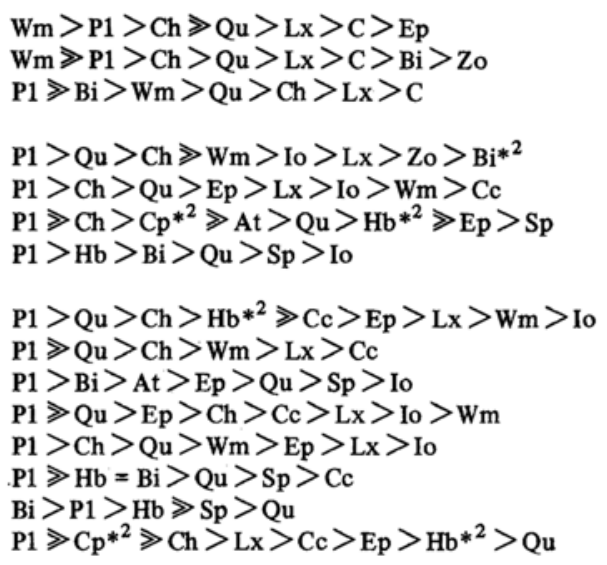

${ }^{* 1}$ Abbreviation for minerals; At: Actinolite, Bi: Biotite, C: Carbonaceous matter, Cc: Carbonate, Ch: Chlorite Cp: Clinopyroxene, Ep: Epidote, Hb: Hornblende, Io: Iron ore, Lx: Leucoxene, Pl: Plagioclase, Qu: Quartz Sp: Sphene, Wm: White mica, Zo: Zoisite.

*2 Relic mineral.

Notice: Quartz and plagioclase occur mostly as relic minerals in rocks belonging to the greenschist facies.

Table 2. Modal compositions of the Kavirondian shales

\begin{tabular}{lcrc}
\hline Sample No. & 1 & \multicolumn{1}{c}{2} & \multicolumn{1}{c}{3} \\
\hline Quartz & 4.2 & 6.3 & 10.1 \\
Plagioclase & 30.6 & 20.3 & 40.4 \\
Biotite & - & 1.0 & 19.5 \\
White mica & 32.3 & 50.1 & 16.2 \\
Chlorite & 25.2 & 10.3 & 4.0 \\
Epidote & 0.8 & 0.5 & - \\
Opaque & 6.6 & 9.8 & 8.3 \\
Others & 0.3 & 1.7 & 1.5 \\
Total & 100.0 & 100.0 & 100.0 \\
\hline
\end{tabular}

geological structure of the System is analyzed by Hoshino et al. (1983). Among seventeen samples submitted to the chemical analyses, three are shales, four are sandstones, eight are matrices of conglomerates, and two are pyroclastics. The age of sedimentation of the Kavirondian System is considered to be $2,800-2,500 \mathrm{Ma}$ ago (Yanagi and Suwa, 1981). The Kavirondian rocks are thermally metamorphosed ranging from lower greenschist facies to lower amphibolite facies by emplacement of the post-Kavirondian granites of 2,450 Ma ago (Dodson et al., 1975; Yanagi and Suwa, 1981).

Constituent minerals of the rock samples are listed in Table 1. Quartz and plagioclase occur mostly as relic minerals in rocks of greenschist facies. Clinopyroxene and hornblende occur as relic minerals in rocks of greenschist facies. Modal analyses of three samples of Kavirondian shale are shown in Table 2.

\section{EXPERIMENTAL}

\section{Rock SAMpLES}

A few pieces of each rock sample were washed with a mixture of $\mathrm{HCl}-\mathrm{HF}$ solution and rinsed with a mixture of methanol-benzene to remove apparent contaminants. From thus cleaned portion, about $10 \mathrm{~g}$ of powder was prepared for each sample, and was submitted to the following chemical analyses.

\section{Total carbon An adequate quantity of} each powdered sample was heated with $\mathrm{H}_{2} \mathrm{SO}_{4}$; $\mathrm{Ag}_{2} \mathrm{CrO}_{4}, \mathrm{~K}_{2} \mathrm{Cr}_{2} \mathrm{O}_{7}$ and $\mathrm{Na}_{2} \mathrm{SO}_{4}$ to decompose organic matter, and generated $\mathrm{CO}_{2}$ gas was 
adsorbed in $\mathrm{Ba}(\mathrm{OH})_{2}$ solution, then the content was measured by the back titration method with $\mathrm{HCl}$ solution.

Carbonate-carbon One gram of each powdered sample was treated with $10 \mathrm{ml}$ of $0.5 \mathrm{M} \mathrm{H}_{2} \mathrm{SO}_{4}$ at $100^{\circ} \mathrm{C}$ for $20 \mathrm{~min}$, and generated $\mathrm{CO}_{2}$ gas was measured by the same method for total $\mathrm{C}$ content.

Organic carbon Organic carbon content was obtained by subtracting carbonate-C content from total $\mathrm{C}$ content.

Total nitrogen Total nitrogen content was measured by the sealed tube digestion method described by Stevenson (1960).

Soluble nitrogen Fifteen $\mathrm{ml}$ of $1 \mathrm{M} \mathrm{KCl}$ was added to $2 \mathrm{~g}$ of each powdered sample. After shaking, the mixture was allowed to stand for one night, and centrifuged, then ammonium content of the supernatant was measured by distillation of ammonia in the micro-Kjeldahl unit and colorimetric estimation with the Nessler's reagent.

Insoluble nitrogen Insoluble nitrogen content was obtained by subtracting soluble $\mathrm{N}$ content from total $\mathrm{N}$ content.

\section{Fixed ammonium-nitrogen}

About $0.5 \mathrm{~g}$ of

each powdered sample was treated with mixed solution of $10 \mathrm{ml}$ of $48 \% \mathrm{HF}$ and $1 \mathrm{ml}$ of $49 \%$ $\mathrm{H}_{2} \mathrm{SO}_{4}$ at $100^{\circ} \mathrm{C}$ for $1 \mathrm{hr}$ to release fixed ammonium from minerals. This treatment decomposes mica minerals which can hold most part of ammonium ions: The decomposition of the mica is observed on the X-ray diffractograms. After the treatment, the mixture was centrifuged and the supernatant was poured off, and then the precipitate was washed with $\mathrm{H}_{2} \mathrm{O}$. The supernatant and the washings were joined and dried to remove HF. The residue was solved in $\mathrm{H}_{2} \mathrm{O}$, and an aliquot of the solution was determined for ammonium-N content: Ammonia in the solution was estimated by the microKjeldahl distillation method followed by colorimetric estimation as described in total $\mathrm{N}$ determination method. As a matter of course, the solution obtained by this method, however, contains soluble ammonium besides fixed ammonium in minerals. Therefore, fixed
ammonium-N content was determined by subtracting the soluble ammonium-N content from the ammonium- $\mathrm{N}$ content obtained by this method.

Above mentioned treatment decomposes mica completely, but on the other hand, there is a problem that this treatment may attack organic matter in the sediments to form ammonium ions. Therefore, prior to adopting this method, release of nitrogen from aspartic acid by this treatment was examined in order to obtain the data as to the effect of the treatment on the organic nitrogen: Aspartic acid was treated with $\mathrm{HF}$ and $\mathrm{H}_{2} \mathrm{SO}_{4}$ solutions in the same condition as that for the samples, and released nitrogen was measured. The experiment revealed that $0.176 \mu \mathrm{g}$ of nitrogen was released from $119.4 \mathrm{mg}$ of the aspartic acid. This value corresponds to $1.4 \%$ of nitrogen of the aspartic acid used. The same kind of experiments have also been carried out by Itihara (1983a) on valine, phenylalanine, leucine which are neutral amino acids and are commonly detected in sediments. According to the experiments, these amino acids are more stable than aspartic acid in the treatment with $\mathrm{HF}-\mathrm{H}_{2} \mathrm{SO}_{4}$ mixture. Therefore, if the samples contain insoluble nitrogen as a form of an amino group, the nitrogen released from the amino group by this treatment is negligible; for example, if $61 \mathrm{ppm}$ of insoluble nitrogen in No. 1 exists as nitrogen of aspartic acid, nitrogen released from the aspartic acid by the treatment is $0.854 \mathrm{ppm}$. Since kerogen is chemically stable and organic matter in Precambrian sediments is almost kerogen, the adopted treatment in this study for fixed ammonium- $\mathrm{N}$ determination may not cause appreciable release of nitrogen from the kerogen in the samples. Conclusively, measured nitrogen in this method does not practically contain nitrogen originated from the kerogen by the treatment.

Organic nitrogen Organic nitrogen content was obtained by subtracting fixed ammonium-N content from insoluble $\mathrm{N}$ content. 


\section{KEROGEN Fractions}

Kerogen fractions were isolated from two samples, Nos. 1 and 2, through the following process (Fujinuki et al., 1974); concentration of kerogen with an Agitair floatation machine, decomposition of silicate minerals with $\mathrm{HF}$, decomposition of sulfide with $\mathrm{NaBH}_{4}$, and purification of the kerogen with $\mathrm{HCl}$. The obtained kerogen fractions were submitted to the following analyses.

Elemental composition $(C, H, N)$ Carbon, hydrogen and nitrogen contents of the kerogen fractions were quantified by analyses of their combution products. The Perkin-Elmer elemental analyzer was used for the quantification. $X$-ray diffraction analyses A small amount of kerogen fraction put on an aluminium slide was scanned with nickel-filtered $\mathrm{CuK} \alpha$ radiation at a rate of $1^{\circ}(2 \theta)$ per min from $40^{\circ}$ to $10^{\circ}$.

\section{Results AND Discussion}

The concentrations of carbonate-carbon, organic carbon, soluble nitrogen, and insoluble nitrogen of the Kavirondian rock samples are listed in Table 3. The results are as follows.
Carbonate-carbon Carbonate- $\mathrm{C}$ is found in most samples. However, maximum concentration of carbonate-C is $0.28 \%$ owing to noncalcareous nature of the samples.

Organic carbon Organic C is found in all samples of shale and its content ranges from 0.12 to $0.22 \%$. One sample of sandstone (No. 7) and two samples of matrix of conglomerate (Nos. 9 and 13) also contain small amounts of organic C, $0.01-0.03 \%$, but most of the sandstone and matrix of conglomerate, and the pyroclastics have no organic $\mathrm{C}$. The distribution of organic $\mathrm{C}$ contents found in the Kavirondian sedimentary rocks is similar to that in Phanerozoic sediments, although the contents are low as compared with those of Phanerozoic sediments. The low contents of the Kavirondian may reflect the low biological productivity during their sedimentation, as inferred from the scarcity of fossils in Archaean age.

As for organic C in Precambrian rocks, considerable amounts of analyses have been reported (e.g., Dungworth and Schwartz, 1974; Cameron and Garrels, 1980; Hayes et al., 1983). According to Hayes et al. (1983) who reported more than 320 measurements of organic C

Table 3. Concentrations of carbonate- $C$, organic $C$, soluble $N$ and insoluble $N$ of the Kavirondian sedimentary rocks

\begin{tabular}{|c|c|c|c|c|}
\hline \multirow{2}{*}{ Sample No. } & \multicolumn{2}{|c|}{ Carbon } & \multicolumn{2}{|c|}{ Nitrogen } \\
\hline & $\begin{array}{c}\begin{array}{c}\text { Carbonate-C } \\
(\%)\end{array} \\
\text { ( }\end{array}$ & $\begin{array}{c}\text { Organic } \mathrm{C} \\
(\%)\end{array}$ & $\underset{(\mathrm{ppm})}{\text { Soluble N }}$ & $\begin{array}{c}\text { Insoluble N } \\
\text { (ppm) }\end{array}$ \\
\hline \multicolumn{5}{|l|}{ Shale } \\
\hline 1 & 0.01 & 0.15 & 1 & 61 \\
\hline 2 & 0.01 & 0.22 & 3 & 54 \\
\hline 3 & 0.00 & 0.12 & 2 & 25 \\
\hline \multicolumn{5}{|l|}{ Sandstone } \\
\hline 4 & 0.00 & 0.00 & 2 & 0 \\
\hline 5 & 0.08 & 0.00 & 2 & 0 \\
\hline 6 & 0.04 & 0.00 & 2 & 0 \\
\hline 7 & 0.00 & 0.01 & 1 & 3 \\
\hline \multicolumn{5}{|c|}{ Matrix of Conglomerate } \\
\hline 8 & 0.04 & 0.00 & 3 & 0 \\
\hline 9 & 0.28 & 0.03 & 2 & 1 \\
\hline 10 & 0.02 & 0.00 & 3 & 0 \\
\hline 11 & 0.11 & 0.00 & 3 & 0 \\
\hline 12 & 0.00 & 0.00 & 4 & 0 \\
\hline 13 & 0.02 & 0.01 & 3 & 1 \\
\hline 14 & 0.02 & 0.00 & 1 & 0 \\
\hline 15 & 0.18 & 0.00 & 2 & 0 \\
\hline \multicolumn{5}{|l|}{ Pyroclastics } \\
\hline 16 & 0.06 & 0.00 & 3 & 0 \\
\hline 17 & 0.06 & 0.00 & 7 & 2 \\
\hline
\end{tabular}


content, the contents of Precambrian shales cover substantial ranges, and considerable parts of the measurements show high contents such as $5 \%$. The organic $\mathrm{C}$ contents of the Kavirondian shales fall within the lowest part in the range reported by Hayes et al. However, they attributed their high organic $\mathrm{C}$ contents to the inadequacy of the sample collection because the samples were acquired specifically for organic geochemical and micropaleontological investigations. Therefore, the low organic $\mathrm{C}$ contents of the Kavirondian sedimentary rocks seem to be not specific but conformable to the low biological productivity in that age $(2,500$ 2,800Ma).

Soluble nitrogen Soluble nitrogen examined in this study is ammonium- $\mathrm{N}$ which is soluble in $\mathrm{KCl}$ solution. Therefore, if the samples contain ammonium ions which are exchangeable for potassium ions, the ammonium$\mathrm{N}$ is naturally measured in this part. Most of the Kavirondian rock samples contain this kind of soluble ammonium- $\mathrm{N}$ in a range $1-7 \mathrm{ppm}$. When these values are compared with those of Phanerozoic sediments, the level is low. Phanerozoic shales generally have $\mathrm{n} \times 10 \mathrm{ppm}$ of soluble and exchangeable ammonium-N (Itihara, 1983b; Itihara and Honma, 1983), although the sediments containing clinoptilolite and/or mordenite have large amounts of soluble $\mathrm{N}(\mathrm{n} \times 100 \mathrm{ppm})$ (Itihara, 1983b) because these minerals have much exchangeable ammonium ions owing to the high cation exchange capacity. If the Kavirondian rocks have ammonium derived from recent contaminants, most of the ammonium may be measured in this section. Therefore, the low concentrations of the soluble $\mathrm{N}$ in the Kavirondian sedimentary rocks suggest that the recent contamination may be to a small extent, if any.

Insoluble nitrogen Insoluble nitrogen is contained in sizable amounts $(25-61 \mathrm{ppm})$ in shales. A small amount ( $1-3 \mathrm{ppm})$ of insoluble $\mathrm{N}$ is also found in one sandstone, two matrices of conglomerate and one pyroclastics (Nos. 7, 9, 13 and 17). The analytical error of the adopted method for the determination, however, is 1 or $2 \mathrm{ppm}$. Therefore, sandstones, matrices of conglomerate, and pyroclastics of the Kavirondian System have practically no insoluble $\mathrm{N}$ and have only soluble $\mathrm{N}$, which is considered to be mainly due to contaminants. On the other hand, Phanerozoic shales have much insoluble $\mathrm{N}$ $(\mathrm{n} \times 100 \mathrm{ppm}) \quad$ (Itihara, 1983b; Itihara and Honma, 1983). Comparing with the Phanerozoic shales, the Kavirondian shales are one-tenth in the insoluble $\mathrm{N}$ content.

As for nitrogen contents of Precambrian rocks, there is only a few reports (Milovskiy and Volynets, 1966; Honma and Schwarcz, 1979). Nitrogen content of pelitic hornfels and gneisses from the Superior Province, Canada is 38-42 ppm (Honma and Schwarcz, 1979). Both rocks from the Kavirondian System and Superior Province are of about the same age, 2,700 Ma, and the metamorphic grade of the Kavirondian System is lower than that of the Superior Province.

Fixed ammonium nitrogen and organic nitrogen In Phanerozoic sediments, insoluble nitrogen in shales is composed commonly of ammonium- $\mathrm{N}$ and organic $\mathrm{N}$, because organic $\mathrm{N}$ in the sediments changes into ammonium- $\mathrm{N}$ during diagenesis and the ammonium- $\mathrm{N}$ is finally fixed in minerals of the sediments (Itihara, 1978; Itihara and Honma, 1983). This scheme has been supported by nitrogen analyses of muddy sediments of Japan (Itihara, 1983b). In respect to this scheme, the distribution of fixed ammonium- $\mathrm{N}$ and organic $\mathrm{N}$ in insoluble $\mathrm{N}$ was tested for the Kavirondian shales. The results are given in Table 4. In all shales concerned, most of the insoluble $\mathrm{N}$ is fixed ammonium- $\mathrm{N}$, and organic $\mathrm{N}$ is found only in negligible amounts. The fixed ammonium-N must have been formed from organic matter which was supplied to the sediments from organisms of Archaean age, and have been preserved until the present time. If insoluble $\mathrm{N}$ of these samples is abiotic ammonium in origin, samples from graywackes (Nos. 7, 12-14 in Table 1) should contain some detectable amounts of insoluble $\mathrm{N}$ because the ammonium might be fixed in muddy parts of the graywackes, even though the quantity 
Table 4. Concentrations of organic $N$ and fixed ammonium- $N$ in insoluble $N$ of the Kavirondian shales, and elemental composition of their kerogen fractions

\begin{tabular}{|c|c|c|c|c|c|c|c|c|}
\hline \multirow{3}{*}{$\begin{array}{l}\text { Sample } \\
\text { No. }\end{array}$} & \multicolumn{2}{|c|}{ Insoluble $\mathrm{N}$ of shale } & \multicolumn{6}{|c|}{ Elemental composition of kerogen } \\
\hline & \multirow{2}{*}{$\underset{\text { (ppm) }}{\text { Organic N }}$} & \multirow{2}{*}{$\underset{(\mathrm{ppm})}{\text { Ammonium-N }}$} & \multicolumn{4}{|c|}{ Weight \% } & \multicolumn{2}{|c|}{ Atomic ratio } \\
\hline & & & $\mathrm{C}$ & $\mathbf{H}$ & $\mathrm{N}$ & Ash & $\mathrm{H} / \mathrm{C}$ & $\mathrm{N} / \mathrm{C}$ \\
\hline 1 & 3 & 58 & 64.04 & 1.90 & 0.16 & 26.8 & 0.356 & 0.002 \\
\hline 2 & 2 & 52 & 78.86 & 2.80 & 0.12 & 13.2 & 0.426 & 0.001 \\
\hline 3 & 1 & 24 & & & & & & \\
\hline
\end{tabular}

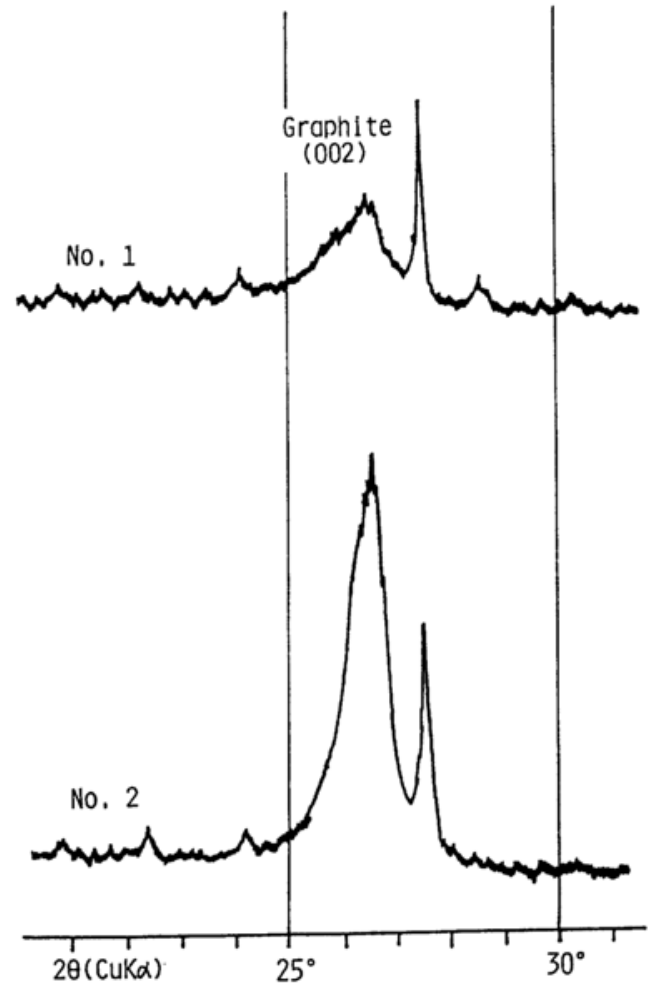

Fig. 1. X-ray diffractograms of kerogen fractions in the kavirondian shales Nos. 1 and 2.

would be smaller than in the samples from shales (Nos. 1-3). But the graywackes have practically no isoluble $\mathrm{N}$. Insoluble $\mathrm{N}$ and organic $\mathrm{C}$ of the Kavirondian shales are considered to be biogenic in origin. These fixed ammonium- $\mathrm{N}$ in the Kavirondian shales are preserved as ammonium ions within mica minerals, because the Kavirondian shales have considerable amounts of mica (white mica and biotite: $32.3-51.1$ vol. \% in Table 2 ), which is the most probable host mineral to hold ammo- nium ions (Honma and Itihara, 1981). Elemental compositions of kerogen fractions The elemental compositions $(\mathrm{C}, \mathrm{H}, \mathrm{N})$ were determined for kerogen fractions in the Kavirondian shales, Nos. 1 and 2. The results are shown in Table 4.

Carbon is the main constituent of kerogen, and besides small amounts of hydrogen and nitrogen are detected. Considerable amounts of ash yielded by combution are inferred to be fluoride and a small amount of pyrite from the $\mathrm{X}$-ray diffraction of the kerogen fractions (Fig. 1).

The atomic ratios of hydrogen to carbon in the kerogen fractions Nos. 1 and 2 are 0.356 and 0.426 , respectively. These values are higher than the values obtained for Archaean rocks (Hayes et al., 1983). But there is a problem that the ash remaining after the organic material has been combusted for analyses will carry excess hydrogen in the form of water of hydration, bound to the ash. Therefore, it can be questioned that the high $\mathrm{H} / \mathrm{C}$ ratios show the low dehydrogenation of the kerogens in the Kavirondian shales. Reports of elemental analyses of Archaean kerogen are too rare to discuss the error arose from the ash.

The atomic ratios of nitrogen to carbon in the kerogen fractions Nos. 1 and 2 are 0.002 and 0.001 , respectively. In contrast with $\mathrm{H} / \mathrm{C}$ ratios, these $\mathrm{N} / \mathrm{C}$ ratios belong to the lower group among the values compiled by Hayes et al. (1983). Low N/C ratios are not due to the denitrogenation during low grade metamorphism but may be due to the intrinsic nature of the organic matter in the shales. The low nitrogen contents of the whole rock samples are due to the low nitrogen contents of the kerogen. 
Organic matter in Precambrian sedimentary rocks is considered to be all kerogen, and the organic $\mathrm{N}$ contents of the samples (Nos. 1 and 2) are calculated at $3-4 \mathrm{ppm}$ from the organic $\mathrm{C}$ contents of the whole rock samples and the $\mathrm{N} / \mathrm{C}$ ratios in their kerogen fractions. This calculated value is practically identical with the organic $\mathrm{N}$ contents determined chemically (Table 4). This coincidence supports also the reliability of the fixed ammonium contents of the shales.

Graphitization degree of kerogen fractions Xray diffractograms of the kerogen fractions showed that the graphitization degree has not yet reached the fully-ordered state. Their graphitization degree roughly corresponds to the graphite- $d_{1}$ according to the classification by Landis (1971). Graphite- $d_{1}$ is in general considered to be formed under the condition of $300^{\circ}-400^{\circ} \mathrm{C}$ and under the greenschist and the blueschist facies conditions. The graphitization degree of the Kavirondian shales is conformable with their metamorphic grade of the greenschist facies (Table 1).

Obvious difference can be recognized between the two diffractograms. The kerogen from sample No. 2 is crystallized better than that from sample No. 1. This is also concordant with their metamorphic grades, i.e., sample No. 1 is of the lower greenschist facies and No. 2 is of the higher greenschiest facies (Table 1).

\section{REFERENCES}

Cameron, E. M. and Garrels, R. M. (1980) Geochemical compositions of some Precambrian shales from the Canadian shield. Chem. Geol. 28, 181-197.

Dodson, M. H., Gledhill, A. R., Shackleton, R. M. and Bell, K. (1975) Age differences between Archaean cratons of eastern and southern Africa. Nature 254, 315-318.

Dungworth, G. and Schwartz, A. W. (1974) Organic matter and trace elements in Precambrian rocks from South Africa. Chem. Geol. 14, 167-172.

Fujinuki, T., Katada, M. and Suzuki, K. (1974) Carbonaceous matter in Permian slates from the southern Kitakami Mountains. Chishitsugaku Zasshi 80,.619 -625 (Japanese).
Hayes, J. M., Kaplan, I. R. and Wedeking, K. W. (1983) Precambrian organic geochemistry, preservation of the record. Earth's Earliest Biosphere 93-134. Edited by J. W. Schopf. Princeton University Press, New Jersey.

Honma, H. and Schwarcz, H. P. (1979) Ammonium content of Archaean rocks of the Superior Province. Okayama Daigaku Onsen Kenkyusho Hokoku 49, 7-13 (Japanese).

Honma, H. and Itihara, Y. (1981) Distribution of ammonium in minerals of metamorphic and granitic rocks. Geochim. Cosmochim. Acta 45, 983-988.

Hoshino, M., Yanagi, T., Suwa, K. and Winani, P. (1983) Geological structure of the Archaean greenstone belt, northwest of Kisumu, Kenya. 8th Prelim. Rep Afr. Studies, Nagoya Univ. 145-156.

Itihara, Y. (1978) Ammonium in biotites from metasedimentary rocks. Chishitsugaku Ronshu No. 15, 233-244 (Japanese).

Itihara, Y. (1983a) Studies on the estimation of fixed $\mathrm{NH}_{4}-\mathrm{N}$ in sedimentary rocks. Studies on Diagenesis of Sedimentary Rocks 69-73. Edited by K. Taguchi, Tohoku Univ.: Sendai.

Itihara, Y. (1983b) The relation between organic and ammonium nitrogen in the Shinjo mudstone samples. Studies on Diagenesis of Sedimentary Rocks 75-80. Edited by K. Taguchi, Tohoku Univ., Sendai.

Itihara, Y. and Honma, H. (1979) Ammonium in biotite from metamorphic and granitic rocks of Japan. Geochim. Cosmochim. Acta 43, 503-509.

Itihara, Y. and Honma, H. (1983) Content and origin of ammonium in biotites of granitic and metamorphic rocks. The Significance of Trace Elements in Solving Petrogenetic Problems \& Controversies 431-444. Edited by S. S. Augustithis, Theophrastus Publ., Athens.

Itihara, Y. and Suwa, K. (1985) Ammonium contents of biotites from Precambrian rocks in Finland: The significance of $\mathrm{NH}_{4}^{+}$as a possible chemical fossil. Geochim. Cosmochim. Acta 49, 145-151.

Landis, C. A. (1971) Graphitization of dispersed carbonaceous material in metamorphic rocks. Contrib. Mineral. Petrol. 30, 34-45.

Milovskiy, A. V. and Volynets, V. F. (1966) Nitrogen in metamorphic rocks. Geochem. Int. 3, 752-758.

Stevenson, F.J. (1960) Microdetermination of nitrogen in rocks and silicate minerals by sealed tube digestion. Anal. Chem. 32, 1704-1706.

Yanagi, T. and Suwa, K. (1981) Rb-Sr radiometric dating of Precambrian rocks in the western part of Kenya. 6th Prelim. Rep. Afr. Studies, Nagoya Univ. 163-172. 